\title{
Diazepam in acute myocardial infarction Clinical effects and effects on catecholamines, free fatty acids, and cortisol
}

\author{
M. Melsom, P. Andreassen, H. Melsom, T. Hansen, H. Grendahl, and L. K. Hillestad \\ From the Medical Department, Sentralsykehuset, Akershus, Nordbyhagen, Norway; and Biological \\ Department, A/S Dumex Ltd., Copenhagen, Denmark.
}

Diazepam is a valuable drug in cases of acute myocardial infarction. The $10 \mathrm{mg}$ intravenous loading dose and the subsequent $15 \mathrm{mg}$ oral dose of diazepam administered three times daily produced safe, pleasant sedation, and reduced the need for analgesics. A much reduced excretion of catecholamines was recorded. It is presumed that diazepam causes a lower stress reaction, which is beneficial in diminishing the incidence of malignant arrhythmias and preventing the existing myocardial injury from spreading.

Acute myocardial infarction represents a stress situation regularly accompanied by raised plasma concentrations of catecholamines, free fatty acids, and cortisol (Vetter et al., 1974), which are among the factors held responsible for the occurrence of such serious complications as malignant arrhythmias, left ventricular failure, and cardiogenic shock (Jewitt et al., 1969). Since the changes are also influenced to a great extent by emotional stress produced by pain and anxiety, a study was performed to measure the effect of sedation in the early phase of myocardial infarction. Diazepam was chosen for this purpose, as we have previously shown that this drug produces safe sedation, with no adverse respiratory or circulatory reactions. Oral and intravenous administration of diazepam was found to be superior to intramuscular injection (Hillestad et al., 1974a); Hillestad, Hansen, and Melsom, 1974b).

This report describes the clinical effects of diazepam in myocardial infarction on the incidence

Received 24 October 1975.

Authors' present addresses :

Magnus Melsom, Dept. IX, Ullevål sykehus, Oslo 1, Norway. Per Andreassen, Medical Department, Horten sykehus, 3190 Horten, Norway.

Haakon Melsom, Det norskeRadiumhospital, Oslo 3, Norway. T. Hansen, Biological Department, A/S Dumex Ltd., Copenhagen, Denmark.

Helge Grendahl, Dept. VIII, Ulleval sykehus, Oslo 1, Norway.

Leif K. Hillestad, Medical Department, Porsgrunnsykehusene, Norway. of malignant arrhythmias, size of infarct, and sedation, and its effect on catecholamines, free fatty acids, and cortisol.

\section{Subjects and methods}

Thirty-eight male patients aged 35 to 70 with proven acute myocardial infarction (admission less than 24 hours from the onset of pain) were diagnosed by means of WHO electrocardiographic criteria and by elevation of plasma aspartate aminotransferase (AST) levels. On admission the patients were randomly divided into a diazepam group and a control group, which later proved to be fairly comparable (Table 1). Patients who had previously been taking drugs that might influence the values (diazepam and diazepam-related compounds, corticoids, ataractics, and methyldopa) were not included in the trial, neither were patients with serious complicating diseases (renal failure, liver cirrhosis) that might interfere with the metabolism of diazepam. Patients who were in cardiogenic shock or in pulmonary oedema on admission were also excluded from the trial.

On admission patients in the diazepam group immediately received $10 \mathrm{mg}$ diazepam (Stesolid) intravenously. One hour later they received an oral dose of $15 \mathrm{mg}$ diazepam and this dose was repeated every 8 hours for three days. Blood samples for determination of plasma-cortisol concentrations (Mattingly, 1962) and free fatty acids (Dole, 1956) 
TABLE 1 Clinical data of 38 patients with acute myocardial infarction (19 patients treated with diazepam and 19 controls)

\begin{tabular}{|c|c|c|c|}
\hline & & Diazepam group & Control group \\
\hline \multirow[t]{2}{*}{ Mean age (y) } & & $\begin{array}{l}56 \pm 6^{\star} \\
\text { (range: } 47-69)\end{array}$ & $\begin{array}{l}57 \pm 7^{\star} \\
\text { (range: } 46-67 \text { ) }\end{array}$ \\
\hline & $0-3 \mathrm{~h}$ & 9 & 5 \\
\hline \multirow{2}{*}{ Duration of pain before admission (no. of patients) } & $3-6 \mathrm{~h}$ & 4 & 7 \\
\hline & $7-24 h$ & 6 & 7 \\
\hline Mean duration of pain before admission (h) & & 6.5 & $6 \cdot 6$ \\
\hline \multicolumn{4}{|l|}{ No. of patients with: } \\
\hline No previous illness & & 9 & 6 \\
\hline Coronary heart disease & & 7 & 10 \\
\hline Hypertension & & 3 & 1 \\
\hline Obliterative atherosclerosis & & 0 & 2 \\
\hline \multirow[t]{2}{*}{ Mean maximum plasma aspartate aminotransferase (AST) (IU) } & & 410 & 514 \\
\hline & Anterior & 10 & 6 \\
\hline \multirow[t]{2}{*}{ Localization of infarct (no. of patients) } & $\{$ Diaphragmatic & 9 & 10 \\
\hline & Posterior & 0 & 3 \\
\hline
\end{tabular}

$\star$ Standard deviation.

were drawn on hospital admission, and thereafter every 12 or 24 hours for 72 hours. In addition, because of the rapid lowering of free fatty acids reported after acute myocardial infarction (Vetter et al., 1974), blood samples were drawn for estimation 4 hours after admission.

The urinary output was collected over 24 hours for each of three consecutive days. Ten $\mathrm{ml} 10$ per cent hydrochloric acid solution were added to the samples from which, after thorough mixing, $100 \mathrm{ml}$ were withdrawn and deep-frozen for later determination of adrenaline, noradrenaline, and dopamine concentrations (Takahashi and Gjessing, 1972).

All patients were treated in a 6-bed intensive coronary care unit. This unit was connected to a 6-channel central oscilloscope which was placed in a separate room. The oscilloscope was constantly supervised by a trained nurse and all arrhythmias seen on the oscilloscope were recorded.

The patients were observed several times a day, and their mental state was rated according to the

TABLE 2 Mental state and need for analgesics in 38 patients with acute myocardial infarction (19 patients treated with diazepam, and 19 controls)

\begin{tabular}{lll}
\hline & $\begin{array}{l}\text { Diazepam } \\
\text { group }\end{array}$ & $\begin{array}{l}\text { Control } \\
\text { group }\end{array}$ \\
\hline No signs of unwanted psychical & & \\
$\quad$ reactions & 15 & 7 \\
Obvious signs of unrest and anxiety & 3 & 6 \\
Severe psychical reactions & 1 & 6 \\
Daily need for analgesics & 3.7 & 5.0 \\
\hline
\end{tabular}

*Number of injections, $10 \mathrm{mg}$ morphine ore quivalent doses of similar drugs. criteria listed in Table 2. Particular attention was paid to signs of diazepam intoxication, such as ataxia, confusion, and euphoria. The need for analgesics was registered as numbers of injections given, either $10 \mathrm{mg}$ morphine or equivalent doses of imilar drugs. Blood samples for determination of concentrations of diazepam and its metabolite, $\mathrm{N}$-desmethyldiazepam, were drawn on hospital admission, and 4, 24, 48, and 72 hours after admission (Arnold, 1975). Plasma aspartate aminotransferase (AST) levels were determined on admission, and several times during the next 2 weeks.

The statistical analysis was done by the $\chi^{2}$-test and Wilcoxon's non-parametric rank test.

\section{Results}

It appears from Fig. 1 that administration of diazepam as described caused a distinct accumulation of diazepam and its metabolite, $\mathrm{N}$-desmethyldiazepam, and the same basic pattern was seen as already discussed by Hillestad et al., 1974b). Continued diazepam treatment had a conspicuously beneficial effect on these patients as compared with the control group (Table 2). It reduced signs of unrest and anxiety $(P<0.01)$. Psychoemotional disturbances were seen in the diazepam group only during the first 24 hours of the trial when the serum diazepam concentrations were below 250 $\mathrm{ng} / \mathrm{ml}$. At the end of the trial, mean diazepam concentrations of $510 \pm 215 \mathrm{ml}$ (SD), and N-desmethyldiazepam concentrations of $281 \pm 110 \mathrm{ng} / \mathrm{ml}$ (SD) were determined. At this time about 70 per cent of the patients in the diazepam group had no memory of the first 24 hours in the coronary unit.

Very few adverse reactions were observed after 


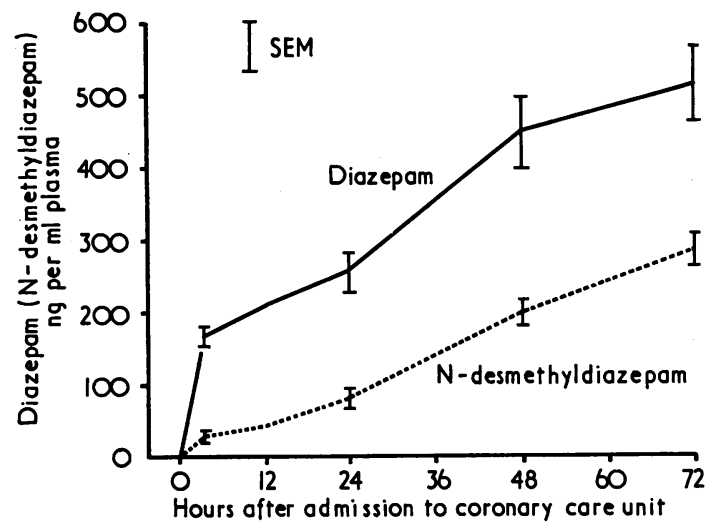

FIG. 1 Mean plasma concentrations of diazepam and $\mathrm{N}$-desmethyldiazepam in 19 patients with acute myocardial infarction treated with diazepam. ( $A$ loading dose of $10 \mathrm{mg}$ i.v., followed by a $15 \mathrm{mg}$ oral dose three times daily for three days.)

diazepam administration. Some patients showed signs of slight ataxia, and a 69-year-old patient became confused and agitated when the serum concentrations of diazepam and $\mathrm{N}$-desmethyldiazepam were $248 \mathrm{ng} / \mathrm{ml}$ and $61 \mathrm{ng} / \mathrm{ml}$, respectively. These adverse reactions quickly abated and disappeared 12 hours after diazepam was discontinued. Otherwise, no adverse reactions were seen-in particular no haemodynamic effects.

Fewer analgesics were needed by patients in the diazepam group as compared with the patients of the control group (Table 2). In comparison with the control group the diazepam group had a lower mean aspartate aminotransferase (AST) level (Fig. 2)

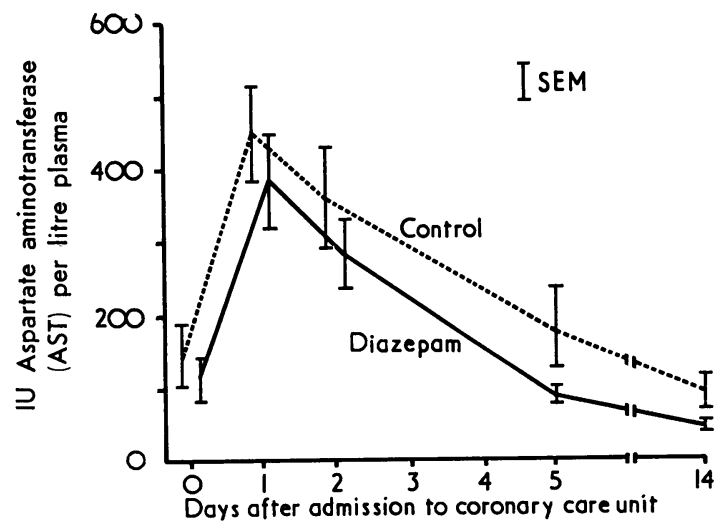

FIG. 2 Mean plasma aspartate aminotransferase (AST) levels in 38 patients with acute myocardial infarction (19 patients treated with diazepam, and 19 controls).
TABLE 3 Incidence of severe cardiac arrhythmias requiring treatment amongst 38 patients with acute myocardial infarction (19 patients treated with diazepam, and 19 controls)

\begin{tabular}{lll}
\hline & $\begin{array}{l}\text { Diazepam } \\
\text { group }\end{array}$ & $\begin{array}{l}\text { Control } \\
\text { group }\end{array}$ \\
\hline $\begin{array}{ll}\text { No. of patients requiring treatment } \\
\text { Supraventricular arrhythmias }\end{array}$ & 10 & 9 \\
Ventricular ectopic beats (more than & 8 & 5 \\
$\quad$ & 6 & 5 \\
Thimin) & 0 & 1 \\
Ventricular tachycardia & 0 & 2 \\
Ventricular fibrillation & 0 & 1 \\
\hline
\end{tabular}

and a lower mean maximum AST value (Table 1), the differences, however, being statistically insignificant $(P>0 \cdot 10)$.

Malignant arrhythmias (ventricular tachycardia, third degree heart block, ventricular fibrillation) were seen only in the control group (Table 3). In the diazepam group, ventricular ectopic beats (more than 6 per minute) occurred only during the initial 12 hours after hospital admission (6 patients), whereas this arrhythmia was observed throughout the whole trial period in the control group (5 patients). No difference was seen between the groups in the incidence of heart failure, hypotension, and cardiogenic shock.

In the diazepam group no patients died during their stay in hospital, whereas in the control group one patient died 28 days after admission.

Patients treated with diazepam slept during most of the trial period, but could easily be awakened.

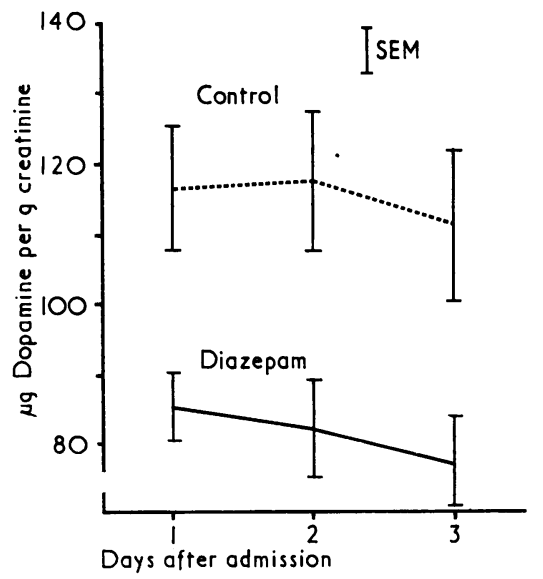

FIG. 3 Mean dopamine excretion per day in 38 patients with acute myocardial infarction (19 patients treated with diazepam and 19 controls). Normal range: $88 \pm 22 \mu \mathrm{g} / \mathrm{g}$ creatinine. 


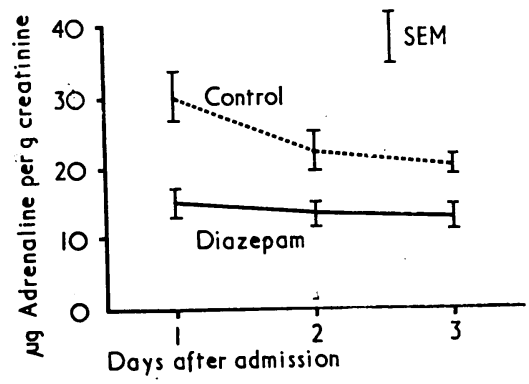

FIG. 4 Mean adrenaline excretion per day in 38 patients with acute myocardial infarction (19 patients treated with diazepam and 19 controls). Normal range: $6 \cdot 1 \pm 1 \cdot 8 \mu \mathrm{g} / \mathrm{g}$ creatinine.

On interview, they expressed feelings of pleasant relaxation and were less concerned about their disease and the future than the patients in the control group.

The administration of diazepam produced a striking effect on the urinary excretion of catecholamines: a high urinary dopamine excretion was seen in the control group, but in the diazepam group it was within the normal range, and the difference between the two groups was highly significant $(P<0.01)$ (Fig. 3).

In both groups the urinary adrenaline concentration was much above normal (Fig. 4). However, diazepam administration caused a significant reduction in adrenaline excretion $(P<0.001)$. The urinary noradrenaline concentration exceeded the

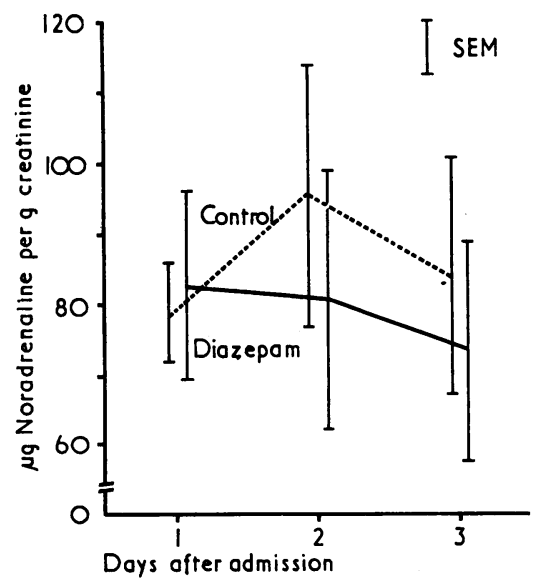

FIG. 5 Mean noradrenaline excretion per day in 38 patients with acute myocardial infarction (19 patients treated with diazepam and 19 controls). Normal range: $20.5 \pm 9 \mu \mathrm{g} / \mathrm{g}$ creatinine.
TABLE 4 Incidence of heart failure, hypotension, and cardiogenic shock among 38 patients with acute myocardial infarction (19 patients treated with diazepam, and 19 controls)

\begin{tabular}{lll}
\hline & \multicolumn{2}{c}{ No. of patients } \\
\cline { 2 - 3 } & $\begin{array}{l}\text { Diazepam } \\
\text { group }\end{array}$ & $\begin{array}{l}\text { Control } \\
\text { group }\end{array}$ \\
\hline $\begin{array}{l}\text { Signs of pulmonary congestion on } \\
\quad \text { consultation }\end{array}$ & 3 & 4 \\
$\begin{array}{l}\text { Pulmonary congestion in addition to } \\
\text { peripheral oedema and/or gallop } \\
\text { rhythm of heart }\end{array}$ & 2 & 3 \\
$\begin{array}{l}\text { Pulmonary oedema } \\
\text { Hypotension }\end{array}$ & 0 & 1 \\
Cardiogenic shock & 3 & 3 \\
\hline Died & 2 & 1 \\
\hline
\end{tabular}

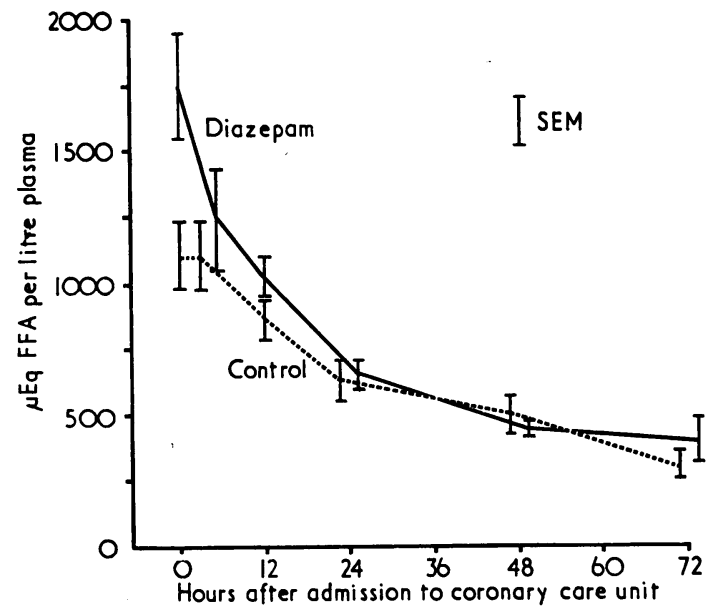

FIG. 6 Mean plasma free fatty acid concentrations in 38 patients with acute myocardial infarction (19 patients treated with diazepam and 19 controls). Normal range: 400 to $800 \mu E q / 1$.

normal value about fourfold, but no significant reduction $(P>0 \cdot 10)$ in the excretion of this substance was observed after diazepam administration (Fig. 5). There seems to be an extreme individual variation in the noradrenaline excretion as compared with excretion of adrenaline and dopamine.

On admission, the mean plasma free fatty acid concentrations in both groups were considerably increased, the diazepam group having the highest level (Fig. 6). After diazepam administration, the free fatty acid concentrations of the diazepam group initially decreased more rapidly than those of the control group. After 4 hours, there was no difference between the control group and the diazepam group, 


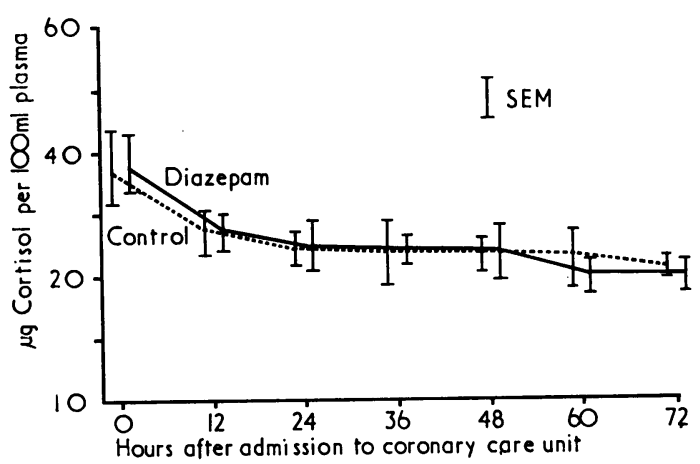

FIG. 7 Mean plasma-cortisol concentrations in 38 patients with acute myocardial infarction (19 patients treated with diazepam and 19 controls). Normal range: 6.3 to $30 \cdot 0 \mu \mathrm{g} / 100 \mathrm{ml}$.

and after 24 hours, the values were within normal limits in both groups.

Diazepam administration did not affect the plasma-cortisol concentrations (Fig. 7). On admission, increased mean values were determined in both groups, showing a rapid decline during the first 12 hours and decreasing to normal range within the next 72 hours. No diurnal variation of plasma cortisol concentrations was seen during the trial.

\section{Discussion}

In most cases, acute myocardial infarction gives rise to serious anxiety (Hackett, Cassem, and Wishnie, 1969). Pain will, in any circumstances, increase every patient's anxiety reactions. The diazepam dosage used in this study provided patients in a serious condition with safe sedation, yet negligible adverse reactions on physical and mental functions.

Previous studies have suggested that orally administered diazepam proves less effective than intravenously administered diazepam, but significantly more effective than intramuscularly administered diazepam (Hillestad et al., 1974a, b). A good correlation was seen between the clinical effect (sedation) and the serum concentration level. Using diazepam as the sedative in myocardial infarction, it was found appropriate, therefore, to initiate treatment with an intravenous injection of the drug (a loading dose) followed by oral diazepam administration.

The clinical effects of the main metabolite, $\mathrm{N}$ desmethyldiazepam, have not yet been completely assessed, but apparently it does not possess any potency as a sedative (Hillestad et al., 1974a, b).

With the exception of a few days' delay for Ndesmethyldiazepam, the accumulation of diazepam and $\mathrm{N}$-desmethyldiazepam occurs mainly during the first week, after which a steady state between cumulation and elimination is maintained. To achieve better sedation a higher loading dose of diazepam should be given initially, and the subsequent oral doses should be reduced gradually to maintain the serum diazepam concentration below $500 \mathrm{ng} / \mathrm{ml}$ (Hillestad et al., 1974a, b).

The amnesia produced by the diazepam treatment may be of special value in attenuating later psychoemotional problems, such as nightmares and cardiac neurosis. Diazepam is reported to be without analgesic effect, so that the reduced need for analgesics during the diazepam treatment is probably the result of an increased tolerance to pain (Bepko, Lowe, and Waxman, 1965). This observation is important, because administration of strong analgesics may suppress respiration, thus causing associated undesirable metabolic effects.

The findings of this study, viz. increased urinary excretion of catecholamines and high plasma free fatty acids and plasma cortisol levels, clearly show that acute myocardial infarction is a stress situation. The well-known correlation between plasma and urinary concentration of catecholamines (Fluck, 1972; Videbaek, Christensen, and Sterndorff 1972) makes it probable that using diazepam to treat patients with acute myocardial infarction caused a decreased plasma level of catecholamines. This conclusion may be of considerable importance, since increased plasma levels of catecholamines may cause ventricular arrhythmias and cardiogenic shock (Jewitt et al., 1969; Siggers, Salter, and Fluck, 1971), and potentiate platelet aggregation (Ardlie, Glew, and Schwartz, 1966).

Adrenaline seems to be more connected with stress than does noradrenaline (Edmondson, Roscoe, and Vickers, 1972; Fluck, 1972). This may explain the lack of effect of diazepam treatment on the noradrenaline excretion.

We believe, despite the fact that continuous 24hour recording tapes were not used, that serious ventricular arrhythmias did not remain undiagnosed. Our observation that diazepam seems to diminish the incidence of ventricular arrhythmias is in accordance with previous publications (Muenster et al., 1967; Van Loon, 1968; Papp, 1969; Cristea, Coeugniet, and Dobrescu, 1970). This diminution may be the result of the decreased plasma catecholamine level, though the antiarrhythmic effect of diazepam should be borne in mind.

An increase in the number of incidents of arrhythmias may be the consequence of high plasma free fatty acid levels (Oliver, Kurien, and Greenwood, 1968; Rutenberg, Pamintuan, and 
Soloff, 1969), and it has been shown that the myocardial oxygen requirement is intensified by free fatty acids. The advantage of the rapid decline in raised free fatty acid levels after diazepam treatment is, therefore, notable.

The diazepam group and the control group were comparable in age distribution and clinical data (Table 1), and the average duration of pain before admission was also similar. However, among the very early admissions, i.e. less than 3 hours' duration of pain, 9 patients were found in the diazepam group and only 5 patients in the control group. The majority of very early cases in the diazepam group may explain the higher initial concentration of free fatty acids in this group. On the other hand, for the same reason a higher incidence of ventricular arrhythmias would be expected in the diazepam group, since the incidence of ventricular arrhythmias is highest in the early stage of myocardial infarction, but this was not seen in the present study.

Previous investigations indicate that the adrenocortical response in myocardial infarction is influenced by the amount of myocardial injury and not only by the stress reaction (Bailey, Abernethy, and Beaven, 1967); Logan and Murdoch, 1966; Chopra et al., 1972; Vetter et al., 1974). This observation may explain the lack of effect of diazepam on the increased cortisol level.

Although the difference in the plasma aspartate aminotransferase levels between the control group and the diazepam group is insignificant, this may suggest another beneficial effect of the drug. It has been shown that diazepam produces coronary vasodilatation in dogs (Abel, Reis, and Staroscik, 1970), and the coronary dilating effect of diazepam in patients with and without coronary heart disease was reported by Ikram, Rubin, and Jewkes (1973).

We conclude that the serious anxiety reactions seen during the initial phase of acute myocardial infarction can be controlled safely by means of diazepam. In addition, administration of diazepam might reduce both the incidence of malignant arrhythmias and the extension of existing injury.

The present study also shows that diazepam may serve to counteract the occurrence of deleterious hormonal imbalance during myocardial infarction.

Seventy-two hours after admission, a reduced daily diazepam dose of $15 \mathrm{mg}$, or less, is recommended considering the accumulation of diazepam as shown in Fig. 1. The dosage of diazepam has to be adjusted when administered to patients previously treated with anxiolytic agents. It should also be remembered that old patients often show a reduced tolerance to diazepam.

\section{References}

Abel, R. M., Reis, R. L., and Staroscik, R. N. (1970). Coronary vasodilatation following diazepam (Valium). British fournal of Pharmacology, 38, 620.

Ardlie, N. G., Glew, G., and Schwartz, C. J. (1966). Influence of catecholamines on nucleotide-induced platelet aggregation. Nature (London), 212, 415.

Arnold, E. (1975). A simple method for determining diazepam and its major metabolites in biological fluids: application in bioavailability studies. Acta Pharmacologica et Toxicologica, 36, 335.

Bailey, R. R., Abernethy, M. H., and Beaven, D. W. (1967). Adrenocortical response to the stress of an acute myocardial infarction. Lancet, $1,970$.

Bepko, F., Lowe, E., and Waxman, B. (1965). Relief of the emotional factor in labor with parenterally administered diazepam. Obstetrics and Gynecology, 26, 852.

Chopra, M. P., Thadani, U., Aber, C. P., Portal, R. W., and Parkes, J. (1972). Plasma cortisol, urinary 17-hydroxycorticoids and urinary vanilyl mandelic acid after acute myocardial infarction. British Heart fournal, 34, 992.

Cristea, E., Coeugniet, E., and Dobrescu, D. (1970). Action anti-arythmique du diazépam, de la méthaqualone et du méprobamate. Le Poumon et le Coeur, 26, 7.

Dole, V. P. (1956). A relation between non-esterified fatty acids in plasma and the metabolism of glucose. Fournal of Clinical Investigation, 35, 150.

Edmondson, H. D., Roscoe, B., and Vickers, M. D. (1972). Biochemical evidence of anxiety in dental patients. British Medical fournal, 4, 7.

Fluck, D. C. (1972). Catecholamines. British Heart fournal, 34, 869.

Hackett, T. P., Cassem, N. H., and Wishnie, H. (1969). Detection and treatment of anxiety in the coronary care unit. American Heart fournal, 78, 727.

Hillestad, L., Hansen, T., Melsom, H., and Drivenes, A. (1974a). Diazepam metabolism in normal man. I. Serum concentrations and clinical effects after intravenous, intramuscular, and oral administration. Clinical Pharmacology and Therapeutics, 16, 479.

Hillestad, L., Hansen, T., and Melsom, M. (1974b). Diazepam metabolism in normal man. II. Serum concentration and clinical effect after oral administration and cumulation. Clinical Pharmacology and Therapeutics, 16, 485.

Ikram, H., Rubin, A. P., and Jewkes, R. F. (1973). Effects of diazepam on myocardial blood flow of patients with and without coronary artery disease. British Heart fournal, $35,626$.

Jewitt, D. E., Mercer, C. J., Reid, D., Valori, C., Thomas, M., and Shillingford, J. P. (1969). Free noradrenaline and adrenaline excretion in relation to the development of cardiac arrhythmias and heart-failure in patients with acute myocardial infarction. Lancet, 1, 635.

Logan, R. W., and Murdoch, W. R. (1966). Blood-levels of hydrocortisone, transaminases, and cholesterol after myocardial infarction. Lancet, 2, 521.

Mattingly, D. (1962). A simple fluorometric method for the estimation of free 11-hydroxycorticoids in human plasma. Fournal of Clinical Pathology, 15, 374.

Muenster, J. J., Rosenberg, M. S., Carleton, R. A., and Graettinger, J. S. (1967). Comparison between diazepam and sodium thiopental during DC countershock. Fournal of the American Medical Association, 199, 758.

Oliver, M. F., Kurien, V. A., and Greenwood, T. W. (1968). Relation between serum-free-fatty-acids and arrhythmias and death after acute myocardial infarction. Lancet, 1, 710.

Papp, C. (1969). New look at arrhythmias. British Heart fournal, 31, 267. 
Rutenberg, H. L., Pamintuan, J. C., and Soloff, L. A. (1969). Serum-free-fatty-acids and their relation to complications after acute myocardial infarction. Lancet, 2, 559.

Siggers, D. C., Salter, C., and Fluck, D. C. (1971). Serial plasma adrenaline and noradrenaline levels in myocardial infarction using a new double isotope technique. British Heart fournal, 33, 878.

Takahashi, S., and Gjessing, L. R. (1972). A fluorometric method combined with thin layer chromatography for the determination of norephinephrine, epinephrine and dopamine in human urine. Clinica chimica Acta, 36, 369.
Van Loon, G. R. (1968). Ventricular arrhythmias treated by diazepam. Canadian Medical Association fournal, 98, 785. Vetter, N. J., Strange, R. C., Adams, W., and Oliver, M. F. (1974). Initial metabolic and hormonal response to acute myocardial infarction. Lancet, 1, 284.

Videbaek, J., Christensen, N. J., and Sterndorff, B. (1972) Serial determination of plasma catecholamines in myocardial infarction. Circulation, 46, 846.

Requests for reprints to Dr. Magnus Melsom, Department IX, Ullevål sykehus, Oslo 1, Norway. 